\title{
Ressecção Endoscópica Escalonada para Amiloidose Extensa do Trato Aéreo-digestivo Superior: Uma Alternativa Eficaz e Viável
}

\section{Endoscopic Escalated Resection to Extensive Amyloidosis of the Upper Aero-digestive Tract: a Feasible and Effective Alternative}

\author{
Thiago Chianca Ferreira*, Carlos Eduardo Fernandes Soares de Melo*, \\ Fernando Martinez Belentani ${ }^{* *}$, Mayko Soares Maia ${ }^{* *}$, Romualdo Suzano Louzeiro Tiago $* * *$. \\ * Graduação. Médico Residente. \\ ** Otorrinolaringologista. Ex Médico Residente. \\ **** Doutor em Ciências pelo programa de Pós-graduação em Otorrinolaringologia e Cirurgia de Cabeça e Pescoço da UNIFESP. Médico Assistente. \\ Instituição: Serviço de Otorrinolaringologia do Hospital do Servidor Público Municipal de São Paulo (HSPM). \\ São Paulo / SP - Brasil \\ Endereço para correspondência: Thiago Chianca Ferreira - Rua Francisco José Longo, 210 - Apto. 72 - Chácara Inglesa - São Paulo / SP - Brasil - CEP: 04140-060 - \\ Telefone: (+55 11) 7691-3738 - E-mail: thiagocferreira@yahoo.com.br \\ Artigo recebido em 12 de Maio de 2009. Artigo aprovado em 27 de Julho de 2009.
}

\section{RESUMO}

Introdução:

Objetivo:

Relato do Caso:

Comentários Finais:

Palavras-chave:

\section{SUMMARY}

Introduction:

Objective:

Case Report:

Final Comments: Keywords:
A amiloidose localizada é uma doença rara, caracterizada pelo depósito extracelular de proteínas que pode ocorrer em várias regiões do corpo. A laringe é o sítio mais comum da doença na região de cabeça e pescoço.

Apresentaremos uma revisão literária e o caso de um paciente com amiloidose extensa em trato aéreodigestivo superior, cuja ressecção foi realizada em quatro etapas.

SMS, 28 anos, disfonia há 4 meses. Exames complementares evidenciaram lesão de grande dimensão em supraglote que foi ressecada em quatro etapas por microlaringoscopia.

A abordagem por microlaringoscopia escalonada mostrou-se eficaz e segura na ressecção de lesão por amiloidose de grande dimensão.

amiloidose, laringe, microcirurgia.

Localized amyloidosis is a rare disease characterized by extracellular deposition of proteins that can occur in various regions of the body. The larynx is the most common site of disease in head and neck. We present a literature review and the case of a patient with extensive amyloidosis in the upper aerodigestive tract, whose resection was performed in four steps.

SMS, 28 years, 4 months ago dysphonia. Complementary exams showed large lesions in supraglottic that was removed in four stages by microlaryngoscopy.

microlaryngoscopy tiered approach was effective and safe resection of lesions in amyloidosis large. amyloidosis, larynx, microsurgery. 


\section{INTRODUÇÃO}

A amiloidose é uma doença caracterizada pelo depósito extracelular de proteínas em várias regiões do corpo $(1,2)$. Pode ser localizada ou sistêmica, adquirida ou hereditária (3). VIRCHow foi o primeiro a usar o termo amiloidose por causa de sua reação tipo amiloide quando tratada comácido sulfúrico. A doença laríngea localizada foi visualizada pela primeira vez por Neumann e Borroe em exames de cadáveres $(2,4)$.

Dentre os tumores benignos da laringe, a amiloidose é responsável por apenas 1\% dos casos. Contudo, é o sítio mais comum da doença amiloide localizada na região de cabeça e pescoço. O sintoma mais comum é a disfonia, podendo estar presente também à dispneia e a disfagia (4).

O exame histopatológico caracteriza-se pela coloração esverdeada birrefringente quando corado pelo vermelho congo.

O tratamento preconizado é a excisão cirúrgica da lesão, a partir de microlaringoscopia. A técnica utilizada pode ser com bisturi, laser de $\mathrm{CO}_{2}$ ou acesso lateral externo em lesões extensas $(1,3,5)$.

O nosso objetivo é relatar a evolução de um paciente com amiloidose extensa em trato aéreo-digestivo superior, cuja ressecção foi realizada de forma escalonada em quatro etapas.

\section{Relato do Caso}

SMS, 28 anos, foi encaminhado com queixa de disfonia com 4 meses de evolução. Negava dispneia ou disfagia. O paciente apresentava uma voz abafada e com pouca projeção. A fibronasofaringolaringoscopia evidenciou uma lesão expansiva de coloração amarelada no ligamento ariepiglótico e prega vestibular do lado direito, limitado à região supra-glótica (Figura 1). Na tomografia computadorizada (TC) foi evidenciada uma lesão expansiva heterogênea com contornos irregulares, se estendendo para prega vestibular e ventrículo do lado direito (Figura 2). A biópsia corada pelo vermelho congo e examinada à microscopia de polarização (birrefringência esverdeada) comprovou tratarse de amiloidose laríngea. O paciente foi encaminhado para investigação clínica quantoà presença de amiloidose sistêmica com exames adequados como: hemograma, coagulograma, AST, ALT, fosfatase alcalina, bilirrubinas totais e frações, ureia, creatinina, ácido úrico, glicemia, cálcio sérico, proteínas totais e frações, proteína $\mathrm{C}$ reativa, VHS, provas reumatológicas, eletrocardiograma, radiografia de tórax e ultrassonografia abdominal e todos foram negativos.

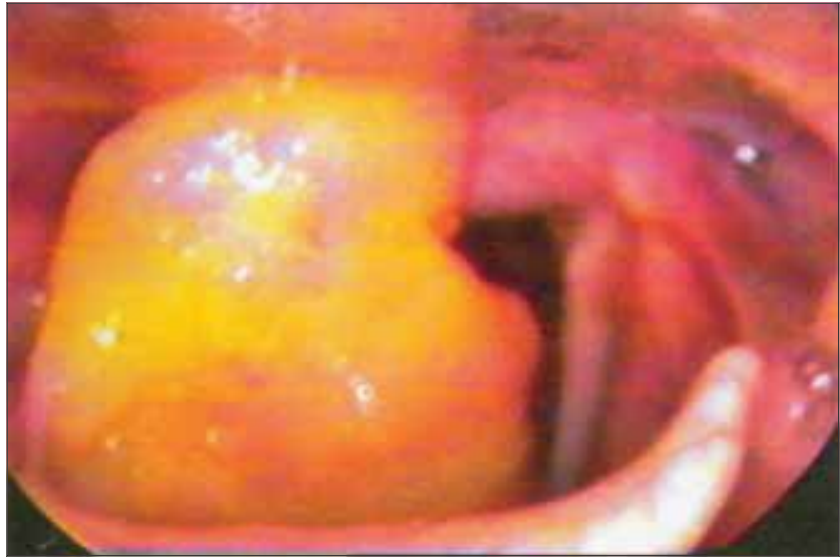

Figura 1. Telelaringoscopia aonde pode ser observada lesão localizada na região supra-glótica (prega ariepiglótica e prega vestibular) do lado direito e com obstrução de aproximadamente 60-70\% do ádito laríngeo.

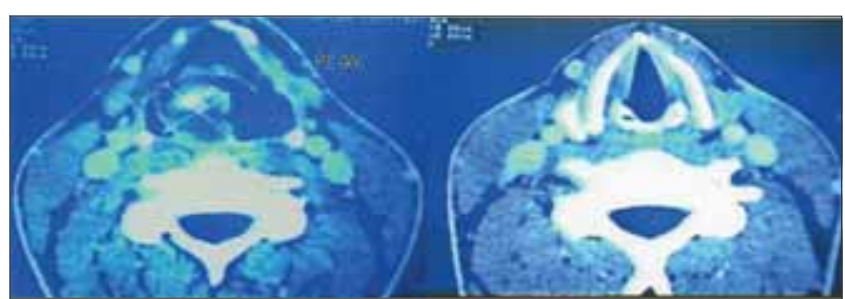

Figura 2. Tomografia computadorizada da região cervical, supra-glote, aonde pode ser observada lesão com densidade de partes moles na prega ariepiglótica do lado direito (esquerda) ausência de lesão na região glótica (direita).

Foi submetido à ressecção cirúrgica por microlaringoscopia. A técnica utilizada foi à ressecção escalonada em quatro etapas com bisturi elétrico para ressecção da lesão laríngea. Entre a primeira e a última etapa, o intervalo foi de cerca de 2 anos.

No primeiro procedimento foi realizada a ressecção da lesão localizada na prega ariepiglótica e a maior parte da lesão da prega vestibular direita, poupando a região posterior da laringe, com o objetivo de evitar estenose nesta região. A lesão residual da região posterior da laringe, localizada acima da aritenoide, foi ressecada no segundo procedimento. Na terceira etapa, retirou-se a lesão localizada no terço posterior da prega vestibular do lado direito.

Entre a terceira e a quarta intervenção, foi observada lesão na base da língua à esquerda (Figura 3), que foi ressecada no quarto procedimento, tendo como diagnóstico histopatológico amiloidose na base da língua. Portanto, esta lesão representou um segundo foco de amiloidose no trato aéreo-digestivo superior.

No quarto é último procedimento foi ressecado foco de amiloidose localizado no terço anterior da prega vesti- 


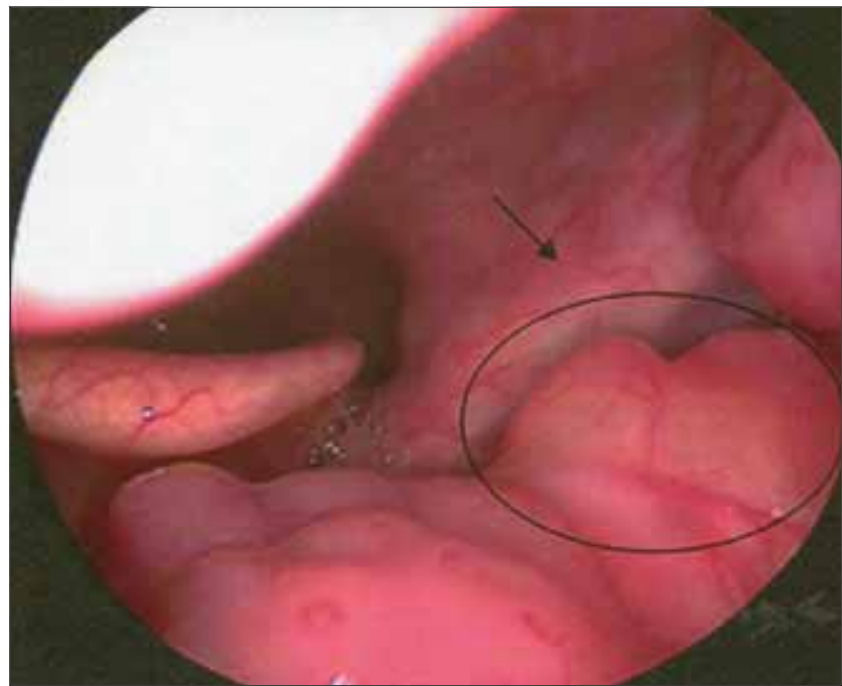

Figura 3. Telelaringoscopia aonde pode ser observada lesão localizada na base da língua, lado esquerdo, de coloração amarelada.

bular do lado direito (Figura 4), além da já descrita, lesão em base de língua. O paciente está sendo acompanhado com exames laringoscópicos periódicos, sem sintomas ou sinais de recidiva da doença (Figura 5).

\section{DISCUSSÃO}

A amiloidose é uma doença rara, caracterizada pelo depósito extracelular de proteínas e de etiologia ainda desconhecida. Bioquimicamente, pode apresentar-se de várias formas distintas, sendo as mais importantes a AL, AA e AB. O tipo AL é derivado de células plasmáticas que contém cadeias leves de imunoglobulina kappa e lambda, pode ser localizado ou sistêmico, e está associado ao mieloma múltiplo. O tipo AA é formado pelo amiloide sérico A, é uma amiloidose sistêmica, e está associado a doenças inflamatórias crônicas. $\mathrm{O}$ tipo $\mathrm{AB}$ é associado à doença de Alzheimer e casos familiares ocasionais (2).

O local preferencial para a amiloidose laríngea são as pregas ariepiglóticas e vestibulares, e o sintoma mais frequente é a disfonia $(1,3,6)$. Raramente a amiloidose laríngea compõe manifestação da doença sistêmica, sendo, quase sempre, doença restrita à laringe $(3,4)$. O paciente relatado apresentou-se inicialmente com queixa de disfonia e foi evidenciada uma lesão que atingia prega ariepiglótica, pregas vestibulares e ventrículo laríngeo do lado direito, sem comprometer as pregas vocais. A doença sistêmica foi excluída após investigação específica.

A lesão amiloide deve ser retirada cirurgicamente, $\mathrm{e}$ sempre que possível de maneira conservadora $(1,2,3,5,6)$. Outros tratamentos como corticoesteroides, radioterapia e

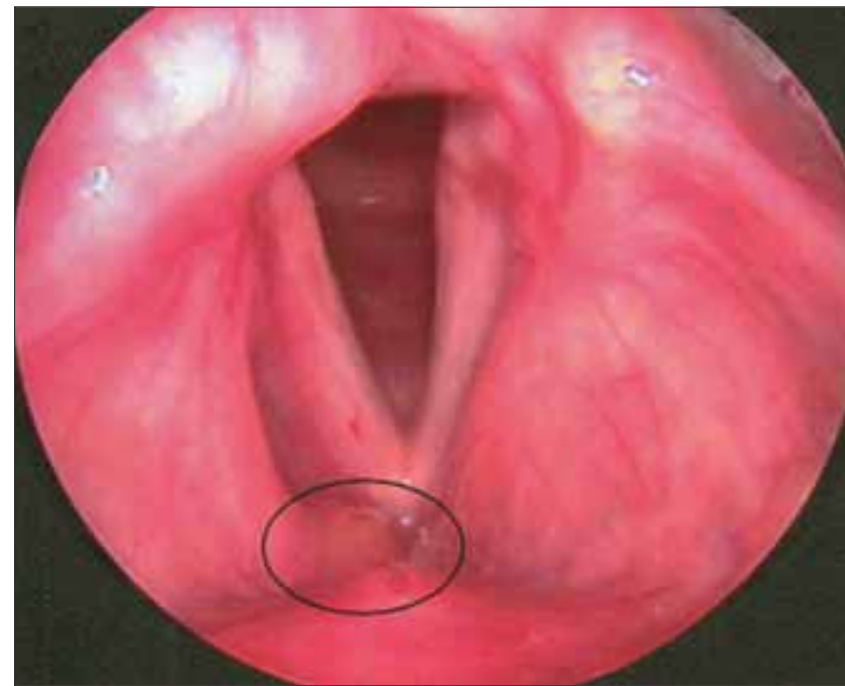

Figura 4. Telelaringoscopia aonde pode ser observada lesão residual anterior, ressecada no último procedimento.

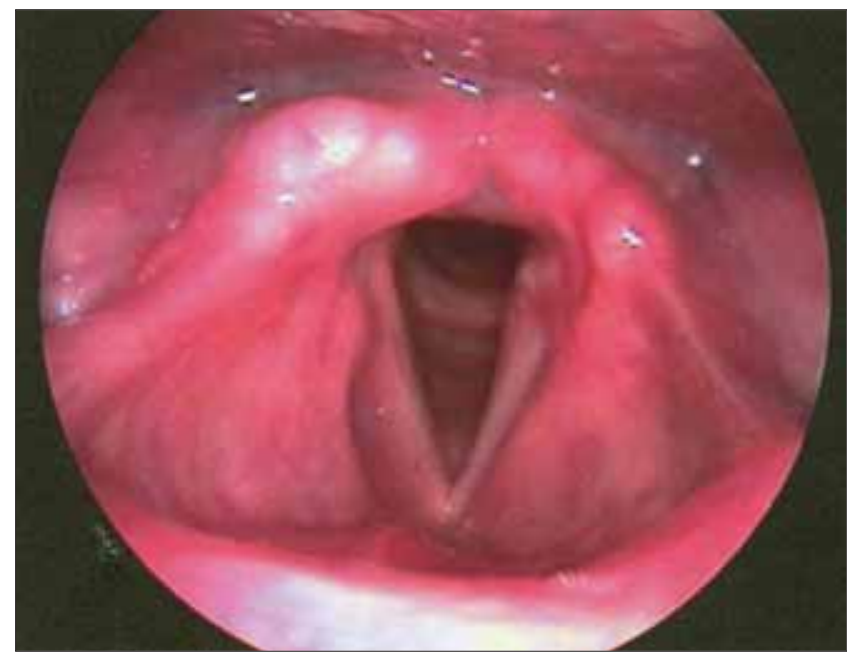

Figura 5. Telelaringoscopia de controle após o quarto procedimento, sem sinais de lesão na região supra-glótica (prega ariepiglótica e prega vestibular).

quimioterapia mostraram-se ineficazes (5). Para doença ampla ou com múltiplas recidivas, KenNedy e PATel usaram a técnica de acesso lateral externo, demonstrando bons resultados nos dois casos submetidos ao tratamento cirúrgico (4). Entretanto, a abordagem externa para ressecção de amiloidose laríngea extensa está relacionada à cicatriz cervical e a certo grau de morbidade (disfagia e disfonia). O paciente relatado foi abordado por microlaringoscopia, com a remoção da lesão sendo realizada com bisturi elétrico, em quatro etapas, visando evitar ressecções amplas e possível formação de sinéquias e estenose laríngea. O resultado foi satisfatório, pois o paciente apresentou completa remissão dos sintomas e a lesão foi completamente ressecada. 
Enfatizamos que esta conduta é possível quando estamos diante de um paciente cooperativo, no qual temos segurança de que o seguimento será feito de maneira satisfatória.

\section{COMENTÁRIOS FINAIS}

A amiloidose é uma doença rara que o otorrinolaringologista deve pensar como diagnóstico diferencial nas lesões laríngeas. Quando diagnosticada, deve ser afastada a possibilidade de doença sistêmica associada. O tratamento cirúrgico de lesões extensas pode ser realizado a partir de microlaringoscopia em duas ou mais etapas. Este tipo de abordagem mostrou-se eficaz e segura no tratamento de um paciente com amiloidose localizada no trato aéreo-digestivo superior (região supraglótica e base de língua).

\section{REFERÊNCIAS BIBLIOGRÁFICAS}

1. Dedo H, Izdebski K. Laryngeal amyloidosis in 10 patients. Laryngoscope. 2004, 114:1742-6.
2. Alaani A, Warfield AT, Pracy JP. Management of laryngeal amyloidosis. J Laryngol Otol. 2004, 118:279-83.

3. Penner C, Muller S. Head and neck amyloidosis: a clinicopathologic study of 15 cases. Oral Oncology. 2006, 42:421-9.

4. Kennedy TL, Patel NM. Surgical management of localized amyloidosis. Laryngoscope. 2000, 110:918-23.

5. Avitia S, Hamilton JS, Osborne RF. Surgical rehabilitation for primary laryngeal amyloidosis. Ear Nose Throat J. 2007, 86:206-8.

6. Thompson LDR, Deringer GA, Wenig BM. Amyloidosis of the larynx: a clinicopathologic study of 11 cases. Mod Pathol. 2000, 13:528-35. 